Proceedings of the 2012 Winter Simulation Conference

C. Laroque, J. Himmelspach, R. Pasupathy, O. Rose, and A.M. Uhrmacher, eds

\title{
PRELIMINARY RESEARCH IN DYNAMIC-BIM (D-BIM) WORKBENCH DEVELOPMENT
}

\author{
Ravi Srinivasan \\ Charles Kibert \\ University of Florida \\ M.E. Rinker Sr. School of Building Constr. \\ College of Design, Construction \& Planning \\ Gainesville, FL 32611, USA \\ Siddharth Thakur \\ Ishfak Ahmed \\ University of Florida \\ Dept. of Mechanical \& Aerospace Engg. \\ College of Engineering \\ Gainesville, FL 32611, USA
}

\author{
Paul Fishwick \\ Zachary Ezzell \\ University of Florida \\ Dept. of Computer \& Info. Science and Engg. \\ College of Engineering \\ Gainesville, FL 32611, USA \\ Jaya Lakshmanan \\ SILPA Research \\ Gainesville, FL 32608, USA
}

\begin{abstract}
Past and ongoing research efforts toward seamless integration of building design and analysis have established a strong foothold in the building community. Yet, there is lack of seamless connectivity between Building Information Modeling (BIM) and building performance tools. D-BIM Workbench provides an essential framework to conduct integrated building performance assessments within BIM, an environment familiar to all stakeholders. With tighter tool integration within BIM, this open-source Workbench can be tailored to specific analysis such as energy, environmental, and economic impact of buildings. The Workbench, currently under development, will enable on-the-fly simulations of building performance tools to design, operate, and maintain a low / Net Zero Energy (NZE) built environment and beyond. This paper discusses the preliminary research in D-BIM Workbench development such as the Workbench architecture, its open-source environment, and other efforts currently under progress including integration of 3D heat transfer in the Workbench.
\end{abstract}

\section{INTRODUCTION}

Building design and engineering is a complex process that involves participation of multiple stakeholders in a coordinated manner for efficient use of human and energy resources. Integration frameworks provide the necessary stage for such collaborations. Such frameworks include integration of building performance tools for design decision-making. There are integration tools that support building performance assessments ranging from daylighting studies to airflow simulations, with a common goal of optimizing building energy- and environmental- impacts. Establishing such an environment requires standard description of product models that define individual data objects and relationships to objects within the model, in a hierarchical representation. The formalization of STEP (ISO-10303, 1994) using EXPRESS data modeling language paved way for the development of more such integration. Particularly for built environments, the Industry Foundation Classes (IFC), which is based on object-based inheritance hierarchy for alleviating interoperability issues, is significant (BuildingSMART 2012). 
IFC, the neutral model for Architectural-Engineering-Construction (AEC) industry, is slated to become an official international standard ISO-16739. Moreover, it has become the catalyst for the exponential growth of a, now, well-known collaboration framework, the BIM. Several research attempted such integration starting from myriad, yet powerful, thermal / daylighting analysis, to more seamless integration of wireless sensor network with performance tools - a cyber-physical systems' approach. Since the design of standard product model representation, there had been remarkable increase in research efforts leading to robust tools. Thus, for the purposes of this paper, the development of integration tools is discussed under two, broadly classified groups namely, the pre- and post IFC phases, table 1.

\subsection{Pre- IFC Integration Tools}

One of the earliest attempts in tool integration is the Integrated Design Databases (IDD) using GLIDE (Eastman and Henrion 1977; Eastman 1979a) for design activities related to architectural and engineering. Although, this work did not initially focus on assessing building energy- or environmental- impacts, it paved way for the creation of a Design Information System or DIS (Eastman 1979b). DIS used abstraction hierarchies to support different design operations through analysis and synthesis models. Such a system not only allowed members of design team to access common data, but it permitted linkages to external analysis programs such as structural, thermal, cost, and piping and distribution sizing. This extended to Computer Aided Engineering and Architectural Design System or CAEADS (Eastman 1979b) which emerged as a fully developed system for architectural applications.

With greater emphasis on building energy efficiency in early 1970's, research focused on promoting energy efficiency at the drawing board, i.e., offering tools that designers can rely for performance- related analysis. Notable among them include, Advanced Energy Design and Operations Technologies or AEDOT (Pohl et al. 1992) that used an Intelligent Computer-Aided Design System or ICADS framework (Pohl et al. 1988). Pohl (1996) ICADS with dynamic agent technology was then developed - it is the Knowledge-based Object-Agent Collaboration system, also referred to as KOALA. At the same time, the concept of unified models was used in model representation. Using constraints, these unified models were used to identify design strategies as in the case of ARMILLA (Haller 1985). An A4 prototype of ARMILLA using a modular building approach (Gauchel et al. 1993). In spite of several research attempts in integration tools in this early period of design performance analysis, there was no one binding model representation for data transfer between tools (i.e., researchers were using independently built schema for model representation and data transfer); each of the tools relied on their own representation, and this posed difficulties for widespread use of such tools. However, the development of EXPRESS language and, later, the formalization of STEP provided the necessary standard for such representation, and, among others, spearheaded the integration efforts, as discussed below.

\subsection{Post- IFC Integration Tools}

Post- IFC, the integration tools took advantage of the standard product model representation which helped interoperability to a greater extent. The COMBINE (Augenbroe 1992) and COMBINE-2 (Augenbroe 1995) projects demonstrated the potential of linking existing tools such as energy, daylighting, and others. As noted earlier, model representation using EXPRESS language and later, the formalization of STEP, and now, the IFC standard, are significant steps in tool integration. EXPRESS language became the binding block of the Knowledge-based Design Support or KNODES framework (Rutherford 1993). The Building Design Advisor or BDA used process-logic control for automating activation processes (Papamichael 1999). A Decision Desktop in BDA allowed designers to conduct multi-criteria analysis based on light illuminance, energy use, etc. Yet, it did not offer automated geometry design variations, rather assigned 'smart' values from a prototype database. A similar approach was attempted by Soebarto and Williamson (1999) in the development of a Designer Orientated Performance Evaluation approach used ENER-WIN software. This approach performed benefit-cost ratio for multi-criteria energy- and environmental- assessment. 
Major advancement in integration tools was realized with SEMPER (Mahdavi et al. 1997). This environment provided an active, multi-aspect design environment. Later, this was expanded to web-based in SEMPER II or S2 (Lam et al. 2004). A similar progression was reached with the Design Analysis Integration (DAI). This Workbench offered a process-centric workbench to overcome the limitations of the, then, data-centric interoperability approaches (Augenbroe and de Wilde 2003). The inclusion of temporal databases with IFC to develop an open, dynamic, and temporal building model is yet another attempt to create intelligent, adaptable buildings (Grzybek et al. 2010). In this building model representation, IFC is improvised with dynamic capabilities of temporal databases in order to mine, learn, and dynamically respond to changes in building states.

Recent developments in Building Controls Virtual Test Bed or BCVTB (Wetter 2011), SimModel (O’Donnell 2011), and Simergy (See et al. 2011) are noteworthy milestones in integration tools. While BCVTB provided the software environment for co-simulation, SimModel is expected to offer interoperability between BIM and energy simulation engines. And, Simergy is expected to, among others, offer an intelligent decision support using EnergyPlus. The co-development of BCVTB, SimModel, and Simergy environment is set to impact the AEC industry considerably, particularly the engineering professionals for evaluating energy efficiency strategies and complying with building rating systems.

BCVTB utilizes Ptolemy environment for the design and analysis of diverse systems. This testbed enables coupling of multiple simulation programs through a middleware instead of coupling them directly. In the case of BCVTB, to give an example, the output of one simulation program can be used as an input into another program during run-time. Run-time data exchange is not a substitute for data interoperability, rather it facilitates co-simulation. Building component libraries for use in BCVTB utilizes Modelica, an equation-based language. At the time of writing this paper, the component libraries (Wetter 2011) developed in Modelica are accessible for simulation via a commercial software, Dymola. Nevertheless, owing to the knowledge required to maneuver the software, such developments may have little influence on the part of architects, the primary stakeholders who lead the design- and functional- aspects of buildings. For example, operating the testbed for co-simulation requires, at a minimum, knowledge in computer programming, which may hinder architects', or in some instances, engineers' participation in multi-party analysis. Another recent work is the development of Cyber-physical Building Energy Management System (CBEMS). This system used a tiered integrated approach to energy, lighting, and plugloads estimation integrated with policy learning / artificial intelligence techniques (Wang et al. 2011). CBEMS supports several wireless protocols such as BACnet, KNX, LonWorks, and ZigBee.

Table 1. Summary of integration tools.

\begin{tabular}{|c|c|c|c|c|c|}
\hline \multirow{2}{*}{$\begin{array}{c}\text { Integration } \\
\text { Tool }\end{array}$} & \multicolumn{2}{|c|}{ Tool Overview } & \multicolumn{2}{|c|}{ Performance Analysis } & \multirow[t]{2}{*}{ Schema } \\
\hline & Approach & Intelligence & Integrated Tools & Sensors & \\
\hline $\begin{array}{l}\text { IDD using } \\
\text { GLIDE }\end{array}$ & $\begin{array}{l}\text { Abstraction hierarchies with } \\
\text { analysis and synthesis mod- } \\
\text { els }\end{array}$ & Rule-based & - & - & - \\
\hline $\begin{array}{l}\text { DIS \& } \\
\text { CAEADS }\end{array}$ & $\begin{array}{l}\text { Design exploration using } \\
\text { GLIDE and abstract repre- } \\
\text { sentations }\end{array}$ & Rule-based & $\begin{array}{l}\text { Structural, Thermal, Cost, } \\
\text { Piping and Distribution Siz- } \\
\text { ing analyses }\end{array}$ & - & - \\
\hline $\begin{array}{l}\text { ARMILLA, } \\
\text { A2 proto- } \\
\text { type of } \\
\text { ARMILLA }\end{array}$ & $\begin{array}{l}\text { Constraint- based (central- } \\
\text { ized control) unified model; } \\
\text { design strategies }\end{array}$ & $\begin{array}{l}\text { Dynamic } \\
\text { constraint- } \\
\text { based }\end{array}$ & $\begin{array}{l}\text { Spatial layout and mechani- } \\
\text { cal systems }\end{array}$ & - & - \\
\hline $\begin{array}{l}\text { AEDOT us- } \\
\text { ing ICADS }\end{array}$ & $\begin{array}{l}\text { Routine-based integration } \\
\text { using a blackboard. }\end{array}$ & Rule-based & $\begin{array}{l}\text { Energy Standards, Building } \\
\text { Mass, Daylighting }\end{array}$ & - & - \\
\hline $\begin{array}{l}\text { A4 Proto- } \\
\text { type of } \\
\text { ARMILLA }\end{array}$ & $\begin{array}{l}\text { Integrated modular building } \\
\text { model approach }\end{array}$ & $\begin{array}{l}\text { Dynamic } \\
\text { constraint- } \\
\text { based }\end{array}$ & Same as ARMILLA & - & - \\
\hline KNODES & $\begin{array}{l}\text { Knowledge-based design } \\
\text { framework }\end{array}$ & $\begin{array}{l}\text { Knowledge- } \\
\text { based sys- } \\
\text { tem }\end{array}$ & $\begin{array}{l}\text { Natural lighting; Energy; } \\
\text { Energy design; Spatial ana- } \\
\text { lyzer; Structural; Costing }\end{array}$ & - & $\begin{array}{l}\text { EXPRESS- } \\
\text { G }\end{array}$ \\
\hline
\end{tabular}


Srinivasan, RS., Kibert, CJ., Fishwick, P., Ezzell, Z., Lakshmanan, J., Thakur, S., Ahmed, I.

Table 1. Summary of integration tools (continued).

\begin{tabular}{|c|c|c|c|c|c|}
\hline \multirow{2}{*}{$\begin{array}{c}\text { Integration } \\
\text { Tool }\end{array}$} & \multicolumn{2}{|l|}{ Tool Overview } & \multicolumn{2}{|c|}{ Performance Analysis } & \multirow[t]{2}{*}{ Schema } \\
\hline & Approach & Intelligence & Integrated Tools & Sensors & \\
\hline $\begin{array}{l}\text { COMBINE, } \\
\text { COMBINE- } \\
2\end{array}$ & $\begin{array}{l}\text { Integrated environment for } \\
\text { energy and HVAC tools in } \\
\text { COMBINE. Used Petri Nets } \\
\text { concepts in COMBINE-2 }\end{array}$ & - & Energy, HVAC Tools & - & $\begin{array}{c}\text { EXPRESS, } \\
\text { STEP }\end{array}$ \\
\hline $\begin{array}{l}\text { Designer } \\
\text { Orientated } \\
\text { Perfor- } \\
\text { mance } \\
\text { Evaluation } \\
\end{array}$ & $\begin{array}{l}\text { Multi-criteria Environmental } \\
\text { assessment (uses criteria } \\
\text { weightings) }\end{array}$ & $\begin{array}{l}\text { Benefit-cost } \\
\text { ratio }\end{array}$ & $\begin{array}{l}\text { Energy (ENER-WIN); Emis- } \\
\text { sions; Thermal comfort; } \\
\text { Costing; Environmental deg- } \\
\text { radation }\end{array}$ & - & - \\
\hline BDA & $\begin{array}{l}\text { Integrated environment for } \\
\text { design process decision- } \\
\text { making }\end{array}$ & $\begin{array}{l}\text { Process- } \\
\text { logic control } \\
\text { for automat- } \\
\text { ed activation } \\
\text { of processes }\end{array}$ & $\begin{array}{l}\text { Daylight (DElight); Energy } \\
\text { (DOE-2); Lighting (Radi- } \\
\text { ance); Airflow (COMIS); } \\
\text { Cost (EAM) }\end{array}$ & - & $\begin{array}{l}\text { BDA data } \\
\text { metasche- } \\
\text { ma }\end{array}$ \\
\hline KOALA & $\begin{array}{l}\text { Constraint- and functionali- } \\
\text { ty- based decision support } \\
\text { system }\end{array}$ & $\begin{array}{l}\text { Object- (dy- } \\
\text { namic) agent } \\
\text { technology }\end{array}$ & Similar to ICADS & - & - \\
\hline SEMPER & $\begin{array}{l}\text { Active, multi-aspect design } \\
\text { environment with dynamic } \\
\text { links to performance evalua- } \\
\text { tion tools }\end{array}$ & $\begin{array}{l}\text { KBES for } \\
\text { providing } \\
\text { thermal } \\
\text { comfort } \\
\text { feedback; } \\
\text { investigative } \\
\text { project tech- } \\
\text { nique }\end{array}$ & $\begin{array}{l}\text { Thermal (NODEM); Airflow } \\
\text { (Hybrid multi-zone, CFD); } \\
\text { HVAC; } \\
\text { Thermal Comfort (Algorith- } \\
\text { mic routines, KBES); Light- } \\
\text { ing (Radiosity); Acoustics } \\
\text { (Hybrid stochastic); LCA } \\
\text { (Eco-balance) }\end{array}$ & - & $\begin{array}{l}\text { Shared Ob- } \\
\text { ject Model }\end{array}$ \\
\hline DAI & $\begin{array}{l}\text { Four-layered process-centric } \\
\text { workbench (design infor- } \\
\text { mation, structure simulation } \\
\text { models, analysis scenarios, } \\
\text { and software tools) }\end{array}$ & $\begin{array}{l}\text { Process } \\
\text { modeling } \\
\text { and enact- } \\
\text { ment (analy- } \\
\text { sis) }\end{array}$ & $\begin{array}{l}\text { Thermal (EnergyPlus, } \\
\text { PMV); Daylight autonomy } \\
\text { (IDEA-L) }\end{array}$ & - & IFC, XML \\
\hline $\begin{array}{l}\text { SEMPER II } \\
\text { (S2) }\end{array}$ & $\begin{array}{l}\text { Web-based active, multi- } \\
\text { aspect design environment; } \\
\text { used XML for data transfer }\end{array}$ & $\begin{array}{l}\text { Same as } \\
\text { SEMPER }\end{array}$ & Same as SEMPER & - & IFC, XML \\
\hline $\begin{array}{l}\text { Dynamic } \\
\text { Building } \\
\text { Model }\end{array}$ & $\begin{array}{l}\text { Open, dynamic, and tem- } \\
\text { poral building model for in- } \\
\text { telligent, adaptable buildings }\end{array}$ & $\begin{array}{l}\text { Inclusion of } \\
\text { temporal da- } \\
\text { tabases in } \\
\text { IFC to mine, } \\
\text { learn, and } \\
\text { dynamically } \\
\text { respond }\end{array}$ & Thermal (test case) & Physical sensor & IFC \\
\hline $\begin{array}{l}\text { BCVTB / } \\
\text { SimModel / } \\
\text { Simergy }\end{array}$ & $\begin{array}{l}\text { BCVTB: Integrated building } \\
\text { energy and control systems } \\
\text { software; SimModel for data } \\
\text { interoperability services; } \\
\text { Simergy: Offers linkages to } \\
\text { BCVTB \& SimModel. }\end{array}$ & $\begin{array}{l}\text { Matlab rou- } \\
\text { tines (e.g., } \\
\text { optimiza- } \\
\text { tion) is ac- } \\
\text { cessed in } \\
\text { BCVTB, }\end{array}$ & $\begin{array}{l}\text { Thermal (EnergyPlus, Mod- } \\
\text { elica library); Lighting (Ra- } \\
\text { diance); HVAC and controls } \\
\text { (Modelica library); Controls } \\
\text { (Simulink) }\end{array}$ & $\begin{array}{l}\text { Wireless sen- } \\
\text { sor networks } \\
\text { (BACnet); } \\
\text { Hardware con- } \\
\text { nectivity }\end{array}$ & $\begin{array}{l}\text { IFC, XML, } \\
\text { BIM im- } \\
\text { port / ex- } \\
\text { port; } \\
\text { gbXML }\end{array}$ \\
\hline CBEMS & $\begin{array}{l}\text { Web- and BEMS- basd four } \\
\text { tier architecture (data acqui- } \\
\text { sition and interface, automat- } \\
\text { ic computing and executing, } \\
\text { management, and monitor- } \\
\text { ing) }\end{array}$ & $\begin{array}{l}\text { Policy learn- } \\
\text { ing (self- } \\
\text { learning and } \\
\text { self- } \\
\text { computing), } \\
\text { Nash equil- } \\
\text { librium }\end{array}$ & Energy; Lighting; Plug-loads & $\begin{array}{l}\text { Wireless sen- } \\
\text { sor network } \\
\text { uses multi- } \\
\text { agent distribut- } \\
\text { ed systems } \\
\text { (supports } \\
\text { BACnet, KNX, } \\
\text { LonWorks, } \\
\text { ZigBee) }\end{array}$ & XML \\
\hline
\end{tabular}




\section{PRELIMINARY RESEARCH IN D-BIM WORKBENCH DEVELOPMENT}

Advancements in BIM allowed efficient program management of building design, construction, and operation. As BIM offers a collaborative environment for project teams to "talk" to each other, including conducting necessary analysis, decision-making, and documentation, it is widely used in the AEC industry. Among others, the greatest value of BIM to AEC industry is reduced errors and improved work quality. Several organizations have directed the use of BIM for new and existing projects and, accordingly, in some cases, developed guidelines for implementation of BIM for new and existing buildings. US General Services Administration (GSA) released the GSA BIM Guide for Energy Performance as a method to strengthen the reliability, consistency, and usability of predicted building energy use and energy cost results (GSA 2009). Others include, BIM standardization by Finland's Senate Properties (Senate Properties 2007); Statsbygg (2011), the Norwegian government's key advisor in construction and property affairs; the American Society of Heating, Refrigeration and Air-Conditioning Engineers' (ASHRAE) BIM Standard (ASHRAE 2009), to name a few.

\subsection{BIM and Building Performance Tools' Integration}

Past and ongoing research efforts toward seamless integration of building design and analysis have established a strong foothold in the building community. Yet, there is lack of seamless connectivity between BIM and building performance tools. While BIM development focused on semantics and ontologies to support critical building construction contexts, the building performance tools' development immersed into the multitudes of building elemental characteristics and their interactions. Besides lack of seamless connectivity, both BIM and building performance tools have inherent limitations. For example, BIM has rich resource-capability extending the framework to 4D BIM (cost) and 5D BIM (cost and schedule). Still, it lacks the necessary component-level structures to retrieve and assimilate building performancerelated constructs. Similarly, a number of limitations exist in building simulation tools as well that are currently overcome with auxiliary calculations or, in some instances, not modeled at all, e.g., specific building control systems, etc. (Crawley et al. 2005; Tupper et al. 2011).

The integration of BIM and building performance tools is a new field of exploration both in the building science and sustainability research domains. What is vastly missing is the "connecting glue" that is structured with all mappings between BIM and building performance tools, and more. This lack of integration between BIM and building performance tools translates to manual and/or semi-automated procedures of data transfer between tools and, possibly, the creation of redundant and/or erroneous information. This undesirably impacts energy efficiency, productivity, and competitiveness in the AEC industry. Particularly, since buildings worldwide consume over $40 \%$ of all energy, impact due to this problem is noteworthy.

Currently, simple building performance analyses may be conducted directly from within a small number of existing BIM tools e.g., Revit ${ }^{\circledR}$ MEP (2012), Rhinoceros 3D (2012), etc. However, they are not comparable to typical, full-scale simulations conducted using standalone analysis tools such as using EnergyPlus $^{\mathrm{TM}}$ or DOE-2 algorithms. SimModel, an XML-based data model, allows some functionality for data exchange between BIM authoring and building simulation tools, particularly energy analysis. Although SimModel is developed for a new building energy analysis tool, Simergy, it is anticipated to be available as a standalone application for use by building simulationists. Nevertheless, SimModel may not provide a unified environment to conduct energy-environmental analysis. Similarly, a plug-in, DIVA4Rhino (Jakubiec and Reinhart 2011), enabled daylighting simulations to be performed within Rhino ${ }^{\mathrm{TM}}$, a BIM software.

Despite these research efforts, current BIM and building performance tools' integration are at a level that are particularly nascent and do not contribute to the larger goal of sustainability. 


\subsection{Characteristics of BIM Integration Environment}

Most of the performance tools currently implemented and/or integrated with BIM relate to energy use during operation and related emissions, and do not include all other energy inflows required for the particular building to exist, e.g., the energy required for building material manufacturing, maintenance, etc. (Srinivasan et al. 2012). Energy flow boundaries extend beyond individual buildings and the integration environment should be able to capture such flows. In order to expand conscious decision-making to make buildings more sustainable, major steps must be undertaken. One of the fundamental steps is defining the characteristics of such an integration environment. Thus, for tighter coupling of BIM and building performance analysis, and in support of the larger goal of global sustainability, the following characteristics are essential.

\subsection{1 "Dynamic" BIM}

In spite of recent developments in BIM technologies, at present, the real-time feedback approaches established in BIM relate entirely to construction project management updates such as project statuses, etc., and they do not relate to building optimization of environmental, economic, and societal impacts. Thus, in terms of whole building performance optimization, current BIM framework may be rendered as "static."

In other words, although BIM comprises of an enormous database of the building structure, it is not active enough to conduct real-time assessment of buildings including implementation of sensor data and/or control algorithms, in real-time, to offer optimized solutions for assessing building's environmental, economic, and societal impacts. One of the recent research work attempted enhancing IFC for dynamic data acquisition for future mining, learning, and dynamic response (Grzybek et al. 2010). It is likely that SimModel will alleviate some of the issues related to interoperability between BIM and building performance tools, particularly energy analysis. However, energy analysis is only one of the several assessment tools that an architect and/or engineer may utilize during early design development phase or continuous monitoring of buildings during operation and until the building life.

With BIM's widespread adoption by architects and engineers, for low / Net Zero Energy building design-operation-maintenance strategy, it must be acknowledged that continuous monitoring with real-time feedback systems within BIM framework is crucial. In other words, a "dynamic" BIM approach is essential that not only tracks energy flows, but responds to state changes.

\subsubsection{Total Environmental Analysis}

Most of integration tools in the BIM domain focused on energy analysis and may extend to daylighting or similar. However, these analysis tools are just a few in a series of tools that are available for assessing a building's performance during its entire lifetime - from building design to its demolition and material disposal / recycling. What is required is "total environmental analysis" of a building. Several tools exist for such environmental accounting, e.g., Life Cycle Assessment, embodied energy and emissions, exergy, emergy, etc., to name a few. Only standalone integration has occurred so far with some of these tools, rather than a unified approach to assess the building and its environment, in a holistic perspective.

\subsubsection{Interactive, Multi-User Environment for Pervasive Simulations}

BIM is an interactive- and feature- rich platform. This collaboration framework should become a flexible, interactive, multi-user environment for pervasive simulations. Current visualizations, as presented in BIM authoring tools, are pertinent to building design- and construction- representation, and may not offer multiple users to conduct evaluations simultaneously. For example, as the mechanical engineer is "adding" sensors, the architect can evaluate envelope configurations at the same time. 
This is similar to Second Life, a 3D virtual world built by users portrayed as 'avatars' (SecondLife 2012) or Second China project (Fishwick et al. 2008) that integrated modeling methodology, virtual environments, agent-directed simulation, and simulation-based learning. It is imminent that performance simulations, in future, will not be rendered as a step in building design-construction-maintenance process, rather will become pervasive, i.e., become the process itself. Interactive, multi-user environment is a first step toward such integration.

\subsubsection{Extensible Virtual Environment}

In the age of smart grids, assessing buildings in seclusion is entirely inadequate. Take, for example, a university campus setting: there are several campuses that mandated use of BIM models for all new and existing buildings, as in the case of University of Florida (UF). With sensing technologies, it is crucial to monitor energy flow, not within a building, but between buildings and for all types - energy producers and consumers.

Current BIM tools may not be able to represent a collection of buildings, let alone an entire campus. The same holds good for modeling communities, cities, states, countries, and the world. What is needed is an extensible virtual environment that can expand and grow with model data. Enabling such extensible virtual environments will offer integrating tools related to smart grids and more. Tracking movement of building materials, energy used in the manufacturing process, etc., then, all becomes part of this larger environment, e.g., tracking of drywall from a manufacturing unit in China to a new building at UF campus. A critical component of this feature is to allow importing models, at all scales, without data loss and model integrity, and still enable seamless, virtual interactions.

\subsubsection{Open-source Technology}

Simply stated, technologies designed for the benefit of human living and the planet, without doubt, must be freely available and use open-source technology for community participation, globally.

\subsection{Development of Dynamic-BIM Workbench}

A critical component of sustainability in the built environment is to enable all stakeholders share, access, and analyze in an equitable manner, yet utilizing the capabilities that are being offered by developments such as BCTVB, SimModel, and Simergy, and also extend the life of BIM to match their buildings. Currently, the estimated lifetime of a BIM is 1-3 years as it is, typically, shelved after construction although "as-built" BIM model is completed per contractual agreement. Among others, one approach is to conduct building energy- and environmental- analysis from within BIM platform, an environment which is all too familiar to architects and other stakeholders, and is currently the norm for building projects. Such an approach will alleviate the hassle of hopping from software to software or worrying about the limitations of one software over the other including interoperability issues, or turning to the basics of new software and more - all at the cost of project time and dollars.

Presently, a D-BIM Workbench, an open-source, unified, interactive, extensible, and interdependent domain that enables building performance assessments to be conducted from within BIM domain is under development, figure 1. Seamless and consistent data transfer between BIM and building performance assessments is one of the characteristics of the Workbench. With tighter tool integration with BIM, this open-source Workbench can be tailored to specific analysis such as energy, economic, and environmental impact of buildings and its environment. The Workbench will enable on-the-fly simulations of building performance tools to design, operate, and maintain a low / NZE built environment and beyond. The Workbench will be tightly integrated with BCVTB in order to take advantage of existing and future development of Modelica component libraries. 
Srinivasan, RS., Kibert, CJ., Fishwick, P., Ezzell, Z., Lakshmanan, J., Thakur, S., Ahmed, I.

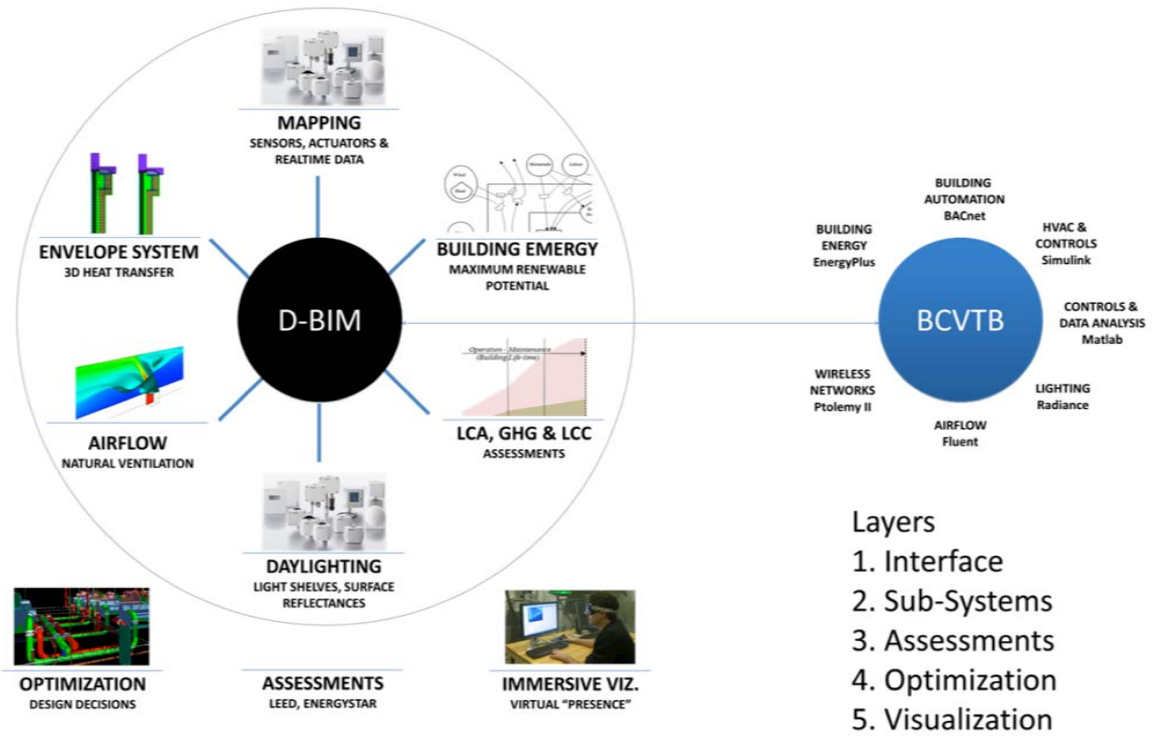

Figure 1. D-BIM Workbench - Overview.

Moreover, with greater emphasis on energy- and environmental- conscious building design and operation, the larger question that needs to be addressed is - are architects and/or engineers equipped to pursue building evaluation in a holistic perspective effectively, not just energy or daylighting, but in its entirety in relation to the environment and within BIM? Among others, one solution lies in the integration of D-BIM Workbench with process-centric workflow, which is documented in Augenbroe and de Wilde (2003), or similar. In other words, based on design queries, determination of analysis workflow is accomplished; all of these conducted within BIM, for one or a collection of buildings in the multi-user, interactive world space. D-BIM Workbench under development is expected to embody all characteristics discussed in section 2.2. Details related to D-BIM Workbench architecture will be presented in a separate manuscript. This paper discusses the preliminary research in D-BIM Workbench development such as the open-source environment for D-BIM and integration of 3D heat transfer in the Workbench.

\subsubsection{Open-Source OGRE-based Environment for D-BIM Workbench}

In the development of D-BIM Workbench, one of the initial research tested the Ptolemy / Revit interface for data transfer. In a typical BIM to Building Energy Modeling (BEM) workflow, the necessary data input for energy analysis is parsed from a BIM to a BEM engine. On the other hand, BEM to BIM workflow transfers energy analysis data back to BIM for visualization. A Revit plug-in was developed to connect the Revit software and Ptolemy model in order to test forward and backward data transfer capabilities. The Ptolemy model used was a modified base model from BCVTB, figure 2. Preliminary work tested data transfer from BIM to energy analysis via BCVTB, with physical sensor data, and displayed the resultant data from energy analysis within BIM all using a simple room geometry. The modification included addition of two actors namely a 'LocalPortListener' and a 'LineWriter.' While the 'LocalPortListener' actor controlled the execution of the Ptolemy model based on the signal it received from Revit, the 'LineWriter' actor streamed the energy analysis result, energy use of the test room in this case, which in-turn was input back to Revit. Thus, using the newly developed "Ptolemy Connector" plug-in, the user placed a sensor (as an object) within the Revit model and mapped the sensor (object) to physical sensor (temperature sensor in this case). This triggered the Ptolemy model to execute analysis using physical sensor data using 'LocalPortListener' actor. The Ptolemy model connected to EnergyPlus using the "EnergyPlus" actor available in BCVTB. The output was streamed back to Revit plug-in via the 'LineWriter' actor, which, then, was displayed in Revit using a TextNote object, figure 3. 


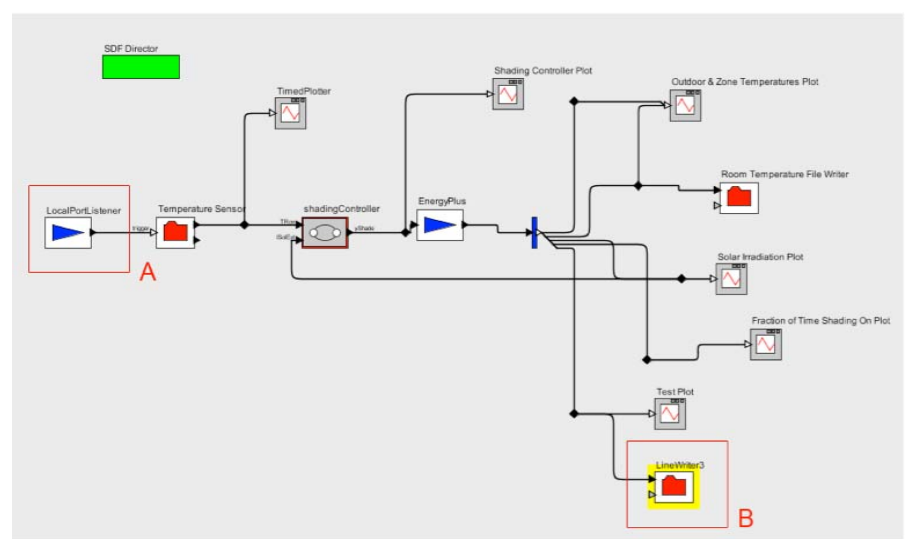

Figure 2. The modifications to the base "Window-Actuator" Ptolemy model (BCVTB, 2011) available as an example for BCVTB: (A) a custom actor for Port listening and (B) a line writer that streams the output from EnergyPlus to a file for display in Revit.

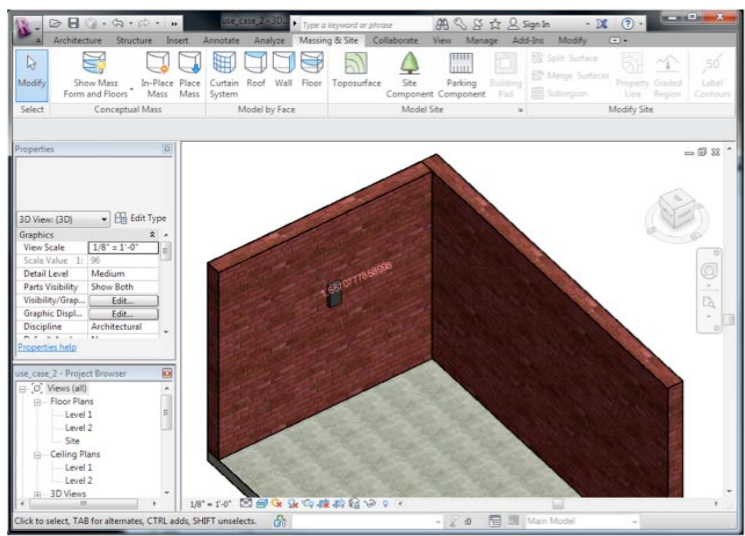

Figure 3. A snapshot of Revit running the

"Ptolemy Connector" plug-in showing EnergyPlus output.

Preliminary tests showed that, for multi-user interaction and visualization in D-BIM Workbench, there were several limitations in Revit. Revit plug-ins have restricted accessibility to external programs owing to lack of multi-thread capability. Per the documentation, Revit's solution to connecting to external programs is to allow developers to create an 'OnIdle' function that Revit will call whenever it is in the 'idle' state. This is not ideal for interactive applications because the 'OnIdle' function is not called at any sort of predictable interval. For example, if the user leaves the mouse cursor still and is not providing any keyboard input, the 'OnIdle' function is never called and, therefore, the visualization is not updated. Presumably, this is because no Revit code is executed unless there is a user-interface event occurring (e.g., moving the mouse or hovering the mouse cursor over a button). Additionally, inept text overlays also pose issues related to visualization of analysis results within Revit.

One way to overcome such issues is to utilize a public-domain library that eliminates the dependence of software-dependent Application Programming Interfaces (APIs) and enables data interoperability from any BIM software using gbXML (GBXML 2012) functionalities and into the Workbench. For BEM execution, an automated (or semi-automated) EnergyPlus file generator from gbXML was developed and tested for simple geometries, and for the purposes of ensuring availability as an open-source tool.

Presently, the open-source Graphics Rendering Engine (OGRE) that utilizes C++ libraries is used for D-BIM Workbench owing to its multi-threaded programming capability, interactive visualization of architectural geometry, and the power of C++ language for GUI development. Moreover, OGRE-based DBIM Workbench allows custom overlays of geometry textures and virtual reality visualizations for greater user experience. From any BIM authoring tool, using an external plug-in installation, the OGRE-based Workbench can be accessed, thus, representing the BIM in D-BIM Workbench. Among others, users can perform fly-through or "walk" into rooms and perform multiple tasks including "adding" and "mapping" sensors. In the next phase of Workbench development, it is anticipated that these sensors will be mapped into respective BIM authoring tools as objects to remove redundancy. Also, since OGRE is a multi-user environment, stakeholders can perform multiple tasks at the same time. An use-case, similar to the Ptolemy / Revit interface, is currently being tested with OGRE-based Workbench.

\subsubsection{D Heat Transfer Analysis Integration}

Preprocessing and parameterization of envelope systems within BIM will offer architects and engineers to identify optimal envelope configurations during design phase. Currently, designers use ASHRAE 90.1 recommended envelope configurations; these are predetermined values and do not alleviate issues related to thermal bridge. Also, existing energy modeling programs do not perform 3D heat transfer analysis. 
For this preliminary work, a Revit plug-in was developed to extract geometry and material data. Parallel work is in progress to extract geometry data from gbXML to remove dependence of specific BIM software APIs. Presently, simple envelope geometry data is extracted from the model. However, in order to model enveloped adjacencies (i.e., intersection of envelope components that develop thermal bridges) particularly the interface of wall with floors, roofs, exterior projections, windows, and other anomalies, rigorous geometry data extraction is required, and is presently under development. Using this integrated approach, architects and/or engineers can calculate envelope thermal conductivities, heat capacities, and densities. The heat transfer algorithm is based on finite volume approach and it is anticipated to extend the 3D meshes into the interiors, spatially, to perform airflow simulations in the next phase of Workbench development.

\section{CONCLUSION}

This paper discussed the preliminary research in D-BIM Workbench development. This framework will pave way to include all tools and techniques that will assist in analyzing the energy, economic, and environmental impact of buildings to realistically achieve a minimum footprint. The expected outcome will have a global outreach for project design teams to conduct early design decision-making, and to operate and maintain low / NZE buildings. It will provide the users a versatile platform to achieving low / NZE buildings using the same BIM domain that is widely used by architects and engineering professionals.

Although preliminary research work in D-BIM Workbench development as discussed in this paper is promising, there are several hurdles particularly the integration of BIM and building performance tools that need to be addressed. The first generation D-BIM Workbench will target architects and engineers for use during early building design phase specifically focusing on selection of envelope systems, energy / daylighting analysis, visualization of energy /daylighting analysis results within OGRE-based environment, and building energy-environmental analysis using emergy (Srinivasan et al. 2012). A state-of-theart building (Institute of Aging) in UF campus will be used as a testbed for D-BIM Workbench.

\section{ACKNOWLEDGMENTS}

This work is supported by the UF Opportunity Seed Fund awarded by the UF Office of Research. The authors would like to thank Patrick Hughes and Mahabir Bhandari at Building Technologies Research \& Integration Center (BTRIC), Oak Ridge National Laboratory (ORNL) for their collaborative support; Bahar Armaghani at UF Facilities Planning and Construction; Pramod Busam and Lakshmanan Velusamy, graduate students at the Department of Computer and Information Science and Engineering, UF.

\section{REFERENCES}

ASHRAE BIM Guide. 2009. American Society for Heating, Refrigeration and Air-Conditioning Engineers, Atlanta, GA.

Augenbroe, G. 1992. "Integrated Building Performance Evaluation in the Early Design Stages." Building and Environment, 27:2, 149-161.

Augenbroe, G. 1995. COMBINE 2, Final Report. Commission of the European Communities, Brussels, Belgium.

Augenbroe, G., and P. de Wilde. 2003. Design Analysis Interface (DAI). Final Report. Atlanta: Georgia Institute of Technology.

Autodesk Inc. Revit ${ }^{\circledR}$ API. Accessed May 15, 2012. http://www.autodesk.com

BuildingSMART. Accessed Jan 20, 2012. http://buildingsmartalliance.org

Crawley, D.B., J.W. Hand, M. Kummert, and B. Griffith. 2005. Contrasting the capabilities of building energy performance simulation programs. US Department of Energy, Washington DC.

Eastman, C., and M. Henrion. 1997. "GLIDE: Language for Design Information Systems." In Proceedings of ACM SIGGRAPH Conference, 1997, San Jose, CA. ACM, New York 
Srinivasan, RS., Kibert, CJ., Fishwick, P., Ezzell, Z., Lakshmanan, J., Thakur, S., Ahmed, I.

Eastman, C. 1979a. "The Representation of Design Problems and Maintenance of their Structure." In Proceedings of IFIPS Working Conference on Application of AI and PR to CAD, Grenoble, France.

Eastman, C. 1979b. "The Computer As a Design Medium." In Proceedings of Eastern Regional ACSA Conference, Carnegie-Mellon University.

Fishwick, P., J. Henderson, E. Fresh, F. Futterknecht, and B. Hamilton. 2008. "Simulating Culture: An Experiment using a Multi-user Virtual Environment." In Proceedings of the 2008 Winter Simulation Conference, Piscataway, NJ.

GBXML. Accessed Jan 10, 2012. http://gbxml.org

GSA. 2009. BIM Guide Series: 02 - GSA BIM Guide for Spatial Program Validation, US General Services Administration.

Gauchel, J., L. Hovestadt, S. VanWyk, and R.R. Bhat. 1993. "Modular Building Models." Chapter in H. Timmermans (ed.), Design and Decision Support Systems in Architecture.

Haller, F. 1985. ARMILLA - Ein Installaionsmodel. Institut fur Baugestaltung der Universitat Karlsruhe," Germany.

ISO. 1994. Industrial Automation Systems and Integration - Product Data Representation and Exchange - ISO 10303. International Organization for Standardization, Geneva.

Jakubiec, J.A., and C.F. Reinhart. 2011. "DIVA 2.0: Integrating Daylight and Thermal Simulations using Rhinoceros 3D, DAYSIM, and EnergyPlus.” In Proceedings of Building Simulation 2011.

Lam, K.P., N.H. Wong, A. Mahdavi, K.K. Chan, Z. Kang, and S. Gupta. 2004. "SEMPER-II: An Internet-based Multi-domain Building Performance Simulation Environment for Early Design Support." Automation in Construction, 13(5), 651-663.

Mahdavi, A., P. Mathew, S. Kumar, and N.H. Wong. 1997. "Bi-directional Computational Design Support in the SEMPER Environment." Automation in Construction 6: 353-373.

O’Donnell, J., R. See, C. Rose, T. Maile, V. Bazjanac, and P. Haves. 2011. "SimModel: A Domain Data Model for Whole Building Energy Simulation." In Proceedings of the 12th Conference of International Building Performance Simulation Association, Sydney, Australia, 14-16 November.

OpenSim. Accessed March 20, 2012. http://opensimulator.org

Papamichael, K. 1999. "Application of Information Technologies in Building Design Decisions." Building Research \& Information, 27:1, 20-34.

Pohl, K.J., J. La Porta, K. Pohl, and J. Snyder. 1992. AEDOT Prototype (1.1): An Implementation of the ICADS Model - Technical Report, CADRU-07-92. CAD Research Center, Design and Construction Institute, College of Architecture and Environmental Design, Cal Poly, CA.

Pohl, K.J.1996. "KOALA: An Object- Agent Design System.” InterSymp.

Pohl, K.J., A. Chapman, and K.J. Pohl. 1996. "CAD Systems for the 21st Century: Some Design Guidelines."

Pohl, K. J., A. Chapman, L. Chirica, and L. Myers. 1998. "ICADS: Toward an Intelligent CAD System." Proceedings of CADRU-02-88, CAD Research Unit, Design Institute School of Architecture \& Enviromental Design, CalPoly, CA.

Rutherford, J.H. 1993. "KNODES: Knowledge-based Design Decision Support." CAAD Futures.

SecondLife. Accessed Feb 18, 2012. http://secondlife.com

See, R., P. Haves, P. Sreekanthan, J. O’Donnell, M. Basarkar, and K. Settlemyre. 2011. "Development of a User Interface for the ENERGYPLUS ${ }^{\mathrm{TM}}$ Whole Building Energy Simulation Program." In Proceedings of the 12th Conference of International Building Performance Simulation Association, Sydney, Australia, 14-16 November.

Senate Properties. 2007. BIM Requirements, Volume 3 - Arch. Design, Senate Properties, Finland.

Soebarto, V.I., and T.J. Williamson. 1999. "Designer Oriented Performance Evaluation of Buildings.” In Proceedings of Building Simulation, Kyoto, Japan.

Srinivasan, R.S., W.W. Braham, D.E. Campbell, and C.D. Curcija. 2012. "Re(de)fining Net Zero Energy: Renewable Emergy Balance of Environmental Building Design." Building and Environment 47: 300315. 
Srinivasan, RS., Kibert, CJ., Fishwick, P., Ezzell, Z., Lakshmanan, J., Thakur, S., Ahmed, I.

Statsbygg. 2011. BIM Manual version 1.2, Norwegian Ministry of Government Administration, Reform and Church Affairs.

Tupper, K., F. Ellen, C. Chan, S. Hodgin, B. Aaron, and M. Jenkins. 2011. "Building Energy Modeling: Industry-wide Issues and Potential Solutions." In Proceedings of the 12th Conference of International Building Performance Simulation Association, Sydney, Australia, 14-16 November.

Wang, S., G. Zhang, B. Shen, and X. Xie. 2011. "An Integrated Scheme for Cyber-Physical Building Energy Management." Advanced in Control Engineering and Information Sciences, 15: 3616-3620.

Wetter, M. 2011. "Co-Simulation of Building Energy and Control Systems with the Building Controls Virtual Test Bed." Journal of Building Performance Simulation, 4:185-203.

\section{AUTHOR BIOGRAPHIES}

RAVI SRINIVASAN is Assistant Professor of Low / Net Zero Energy buildings at the M.E. Rinker, Sr. School of Building Construction, University of Florida. Dr. Srinivasan is a member of the National Fenestration Research Council (NFRC) ANS Standards Committee. Dr. Srinivasan holds M.S. in Engineering from the University of Florida, M.S and Ph.D. in Architecture from the University of Pennsylvania. Dr. Srinivasan is a Certified Energy Manager and a LEED AP. Email: sravi@ufl.edu

CHARLES KIBERT is a Holland Professor at the M.E. Rinker, Sr. School of Building Construction, University of Florida. He is the author of Sustainable Construction: Green Building Design and Construction (John Wiley \& Sons, New York, 2005; 3rd Edition 2012). He holds a B.S. (General Engineering) from the U.S. Military Academy, a M.S. (Nuclear Engineering) from Carnegie-Mellon University, and a $\mathrm{Ph} . \mathrm{D}$. (Mechanical Engineering) from the University of South Florida. He is a registered professional engineer in Florida, a LEED AP and a Green Globes Assessor (GGA). Email: ckibert@ufl.edu

PAUL FISHWICK is Professor of Computer and Information Science and Engineering and Director of Digital Arts and Sciences at the University of Florida. He received the PhD in Computer and Information Science from the University of Pennsylvania, and performs teaching and research in modeling and simulation with an emphasis on human-model interaction. He is a Fellow of SCS, served as General Chair of the Winter Simulation Conference (WSC) in 2000, and was a WSC Titan Speaker in 2009. He currently serves as Chair of ACM SIGSIM. Email: mfishwick@cise.ufl.edu

ZACHARY EZZELL is a doctoral candidate in the Department of Computer Information Science and Engineering at the University of Florida. His research has been published in the Journal of Simulation and he has presented his work at the Winter Simulation Conference. His primary research interest is in human-computer interfaces for simulation and visualization systems. Email: zezzell@gmail.com

JAYA LAKSHMANAN brings in ten years of system analysis and design, process \& quality assurance, energy accounting and sustainability reporting, and environmental audit / compliance experience. She focuses on research in the areas of environmental/ecological accounting and built ecology modeling and reporting. Email: jay@silpainc.com

SIDDHARTH THAKUR is Adjunct Associate Professor in the Department of Mechanical and Aerospace Engineering at the University of Florida. His research expertise are in the areas of Computational Fluid Dynamics, heat transfer, and combustion modeling. He has published extensively in international journals and conference proceedings. Email: sst@ufl.edu

ISHFAK AHMED is a graduate student at the Department of Mechanical and Aerospace Engineering at the University of Florida. His research expertise is in heat transfer. Email: ishahav@ufl.edu 